which has some structural resemblance to tetracaine, has been claimed to be an excellent non-toxic antitussive.

F. C. Copp has surveyed recent advances in the developments of drugs which reduce the blood pressure by selectively affecting tho functioning of the postganglionic sympathetic adrenergic nerves. These adrenergic neuroneblocking agents include quaternary ammonium compounds, large ring compounds containing side-chains with amidoxine, guanidine, and amide groupings and benzyl guanidines. Some of the compounds, including bretylium, guanothidine and two of the benzylguanidines, have found clinical use.

These articles illustrate the efficiency with which organic chemistry can be used in the development of various areas of drug research once a lead and a suitable test system have beon found. It is by this semiempirical approach that many valuable drugs are still obtrined.

E. P. ABRAham

\section{RECENT ADVANCES IN ALDOSTERONE RESEARCH}

\section{Aldosterone}

Edited by E. E. Baulieu and P. Robel. (A Symposium organized by the Council for Intornational Organizations of Modical Sciences established under the joint auspices of UNESCO and WHO.) Pp, xix + 523. (Oxford: Blackwell Scientific Publications, 1964.) 100s.

THIS volume consists of twenty-six papers presented at the symposium on aldosterono held in Prague in August 1963. The participants included most of the research workers actively engaged in research in this field and included biochemists, physiologists, pharmacologists, nephrologists, cardiologists and obstetricians. It is extromoly useful in bringing together under one cover recent developments in the field of aldosterone research. The lively discussions are particularly interesting in underlining points of disagreement.

The presentations are divided into three parts. Part 1 deals with methods of measurement and metabolism. It includes papers on tho rolationship of 18-hydroxycorticosterone to aldosterone, aldosterone metabolism, ronal clearance of aldosterone and its metabolites, measurement of peripheral plasma aldosterone as well as secretion rato, the isolation of human urinary metabolites, and the conjugation of aldosterone and tetrahydroaldosterone in human urine and plasma.

Part 2 deals with its regulation and biological effects. It includes papers on the relation of renin and angiotensin II to aldosterone secretion and sodium excretion, studies on the sheep and rat including renin measurements in hyportensive rats, the rolo of the central nervous system and potassium as well as renal blood supply.

Part 3 deals with arterial hypertension and other pathological manifestations. It includes papers on primary aldosteronism, a familial disorder simulating primary aldostoronism, hyporaldosteronism secondary to renal ischnemia, relationship of aldosterone and angiotensin to human hypertensive disease, estimation of plasma renin, hyperaldosteronism in oederna and idiopathic oedema and the secretion of aldosterone in normal pregnancy and pre-eclampsia.

Much of the discussion was concerned with the role of the renin angiotensin mechanism in relation to aldosterono production. It is clear that there has been much progress recently in methods of estimation of aldosterone and renin. It also emerged that in order to assess the importance of aldosterone in any particular situation neithor the excretion nor even the socretion rates may be sufficient. Howevor, plasma lovels are, at present, both difficult and expensive. Although 18-hydroxycorticosterone is a normal secretory product in the human and its secretory rate is related to aldosterone, it has not been possible to demonstrate in vitro that it is the immediate precursor to aldosterone. Provisional chemical identification of the so-called "3 oxo-conjugate" was also reported.

The papers and discussion covered a wide spectrum of topics related to aldosterone. However, as pointed out by Dr. G. W. Liddle in his concluding remarks, the subject of intra-adrenal biochemical conditions affecting aldosterono synthesis and release received little attention at the conference, as did the subject of the intimate biochemical mechanism of action of aldosterone. This, no doubt, is a reflexion of the fact that these aspects of tho subject are probably not receiving the attention they merit.

Bertha Singer

\section{STEROIDAL ALKALOIDS IN APOCYNACEAE}

\section{Les Alcaloides Stéroidiques des Apocynacées}

Par Robert Goutarel. (Chimie des Substances Naturelles, Nr. 5.) Pp. 289. (Paris: Hermann, 1964.) 48 francs.

$\mathrm{T}$

HIS monograph, with a foreword by M.-M. Janot, is a most welcome addition to the excellent French series Chimie des Substances Naturelles edited by Edgar Lederer, and it more than fully meets the high standards set for the series of providing comprehensive yot concise treatments of relatively narrow groups of natural products, written by authorities who have made major contributions in the field concerned. It is well conceived and its 289 pages embrace a thorough coverage of all aspects of the literature pertaining to the steroidal alkaloids which have been isolated from plants belonging to the family Apocynaceae. It is perhaps unfortunate, however, that the recent discoveries of steroidal alkaloids of the pregnane typo in plants of the families Buxaceae and Euphorbiaceae destroy what had proviously appeared to be a clearly defined chemical classification, thus leaving the content of the work somewhat arbitrarily limited on the grounds of taxonomy alone.

The subject matter is handled in a most logical manner with the monograph being divided into four self-contained chapters covering sources and methods of isolation of the alkaloids; chemical classification, structural elucidation and synthesis of the individual alkaloids; utilization of the alkaloids in the production of steroid hormones and other therapeutic agents; and the biological activities displayed by the alkaloids. Each chapter is clearly written and verbal description is kept to a minimum by the judicious use of well-presented tables which provide a wealth of ready information with minimal effort on the part of tho reader.

Tho first chapter, dealing with the sources and methods of extraction and separation of the different alkaloids, includes an excellent summary of the precise tuxonomical relationships of those species of the Apocynacere in which steroidal alkaloids have been found. Indeed, it should prove of considerable value as a guide to the more likely sources of further alkaloids belonging to the pregnane group.

The second chapter, which covers the fundamontal chemistry of the alkaloids, makes copious use of structural formulae which are sensibly designated by means of arabic and not Roman numerals, serving to make the text very easy to follow. The inclusion of direct reproductions of the infra-red spectra of the individual alkaloids and of line diagrams of solected mass spectra is a most commendable feature. The presentation of tables of physical constants of the parent alkaloids and their derivatives is also an excellent feature and, taken together with the infra-red and mass spectra, these should prove invaluable to the roady identification of any known pregnane alkaloids isolated from other plants in the future. A logical sequence is developed by dividing the alkaloids into 4 main groups-those derived from $5 \alpha$-pregnane, 